\title{
A Systematic Study of the Effects of Naphthalene and Anthracene Substitution on the Properties of PPV Derivative Conjugated Systems
}

\author{
Patrick Lynch \\ Technological University Dublin \\ Luke O'Neill \\ Technological University Dublin, Luke.oneill@tudublin.ie \\ David Bradley \\ Technological University
}

See next page for additional authors

Follow this and additional works at: https://arrow.tudublin.ie/materart

Part of the Physical Sciences and Mathematics Commons

\section{Recommended Citation}

Lynch, P., O'Neill, L. \& Bradley, D. (2007). A Systematic Study of the Effects of Naphthalene and Anthracene Substitution on the Properties of PPV Derivative Conjugated Systems. Macromolecules, , vol. 40, no. 22, pg. 7895-7901. do1: 10.1021/ma070888c

This Article is brought to you for free and open access by the Materials Synthesis and Applications at ARROW@TU Dublin. It has been accepted for inclusion in Articles by an authorized administrator of ARROW@TU Dublin. For more information, please contact arrow.admin@tudublin.ie, aisling.coyne@tudublin.ie, gerard.connolly@tudublin.ie.

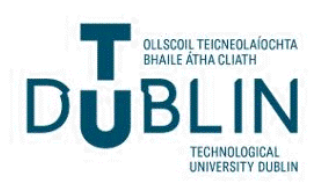


Authors

Patrick Lynch, Luke O'Neill, David Bradley, Hugh Byrne, and Mary McNamara

This article is available at ARROW@TU Dublin: https://arrow.tudublin.ie/materart/8 


\title{
Systematic Study of the Effects of Naphthalene and Anthracene Substitution on the Properties of PPV Derivative Conjugated Systems
}

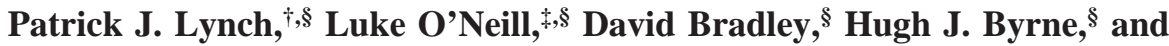 \\ Mary McNamara*,,$\$$ \\ School of Chemical and Pharmaceutical Sciences, Dublin Institute of Technology, Kevin St., \\ Dublin 8, Ireland; School of Physics, Dublin Institute of Technology, Kevin St., Dublin 8, Ireland; and \\ Focas Institute, Dublin Institute of Technology, Camden Row, Dublin 8, Ireland
}

Received April 16, 2007; Revised Manuscript Received July 26, 2007

\begin{abstract}
The systematic synthesis of poly(phenylvinylene) (PPV) derivatives by the Wittig-Horner reaction is reported. The phenyl units of the PPV structure are methodically substituted by naphthyl and anthryl units to form a homologous series of structures. The 2,6 attachment of the vinylene linkage on the anthryl ring provides novel structures that have not been reported before due to their synthetic inaccessibility. The introduction of naphthyl units results in a hypsochromatic shift in the absorption and emission spectra, while the introduction of anthryl units leads to a bathochromatic shift relative to the naphthalene structures. The observed structural variation of the spectroscopic properties is explained in terms of a combination of the increased conjugation of the substituent acene units and the decreased electronic contribution across the vinyl linkage.
\end{abstract}

\section{Introduction}

Since the discovery that poly(phenylvinylene) (PPV) exhibited a strong electroluminescence, there have been many studies involving structural variation of the PPV polymer backbone. ${ }^{1}$ Despite this, there is still a great need for new materials, with improved properties, in order for this technology to fulfill its commercial potential. ${ }^{2}$ In many studies structural variation has been quite nonsystematic, leading to difficulties in determining the specific effects of the relevant moieties. In this study we aim to make structural substitutions in a systematic manner in order to understand their effects on the electronic properties of the systems.

Poly(arylene vinylene)s containing naphthalene of differing substitution patterns have been reported in the past. ${ }^{3}$ For direct comparison to PPV, linkage across the 2,6-positions are most appropriate. Polymers containing this particular arrangement have also been reported; however, they contain other structural variation such as cyano groups across the vinylene bond, ${ }^{4}$ phenylene pendants, ${ }^{5}$ or are insoluble. ${ }^{6}$

Anthracene-containing conjugated polymers have also been reported. ${ }^{7}$ However, those containing vinylene linkages have been poly $(1,4 \text {-anthrylene vinylene })^{8}$ and poly $(9,10$-anthrylene vinylene), ${ }^{9}$ and again for our study, linkages at the 2,6-positions are more desirable.

Soluble PPV derivatives with alkyloxy side chains have been synthesized by many different methods. These include aryl/ ethylene coupling via Heck and Suzuki reactons, ${ }^{10}$ the Gilich, ${ }^{11}$ McMurray, ${ }^{12}$ and Wessling-Zimmermann routes. ${ }^{13}$ However, polymers synthesized by these routes can contain structural defects due to incomplete elimination of precursor functional groups, cross-linking, or other side reactions. ${ }^{14}$ Both the Wittig ${ }^{15,16}$ and the Wittig-Horner reactions ${ }^{17}$ produce polymers of well-defined structure and are suitable for preparing alternating copolymers. ${ }^{18,19}$ However, while the Wittig reaction prodit.ie.

* Corresponding author: Tel +353 1 4024781; e-mail mary.mcnamara@

School of Chemical and Pharmaceutical Sciences.

School of Physics.

$\S$ Focas Institute. duces polymers with both cis and trans geometry across the vinyl bond, it has been shown that the Wittig-Horner route produces practically all trans bonds which will further simplify the structure. ${ }^{20}$ Therefore, this was the route chosen to synthesize structures 1-5 (Figure 1). An octyloxy-substituted PPV derivative (1) was first synthesized to allow for direct comparison of properties with later structures. The introduction of naphthyl units begins first by replacing alternate substituted phenyl units with substituted naphthyl units to give structure (2), and finally all phenyl units were replaced to produce a fully conjugated naphthalene structure (3). In the same manner as for the naphthalene structures, anthryl units are introduced into the polymer backbone first with alternating phenyl units (4) and then with alternating naphthyl units (5).

\section{Results and Discussion}

Our synthetic strategy for polymerization via the WittigHorner route involved synthesizing the appropriate polymeric system from the required dialdehyde and diphosphonate ester. The synthesis of the phenyl intermediates is shown in Scheme 1. 1,4-Di- $n$-octyloxybenzene (6) was synthesized in $74 \%$ yield from commercially available $p$-hydroquinone using the method of Johnstone and Rose. ${ }^{21}$ All spectra and the melting point were as reported. ${ }^{22}$ The bromomethylation of $\mathbf{6}$ using a method similar to that reported ${ }^{23,24}$ carried out in acid-washed glassware using paraformaldehyde and $\mathrm{KBr}$ in acetic acid produced di- $n$ octyloxy-1,4-bis(bromomethyl)benzene (7) in 73\% yield. The Arbuzov reaction yielded 2,5-di- $n$-octyloxy-1,4-xylenediethylphosphonate ester $(8)$ in a $71 \%$ yield. ${ }^{25}$ The dialdehyde was produced from $\mathbf{6}$ by lithiation of the appropriate ortho positions with a $n$-butyllithium-tetramethylethylenediamine (TMEDA) complex ${ }^{26}$ in diethyl ether followed by formylation with DMF. Any monoaldehyde side product which formed was removed by column chromatography, and the purity of 9 was confirmed by NMR spectroscopic analysis.

The synthesis route to the corresponding naphthalene dialdehyde and diphosphonate ester is shown in Scheme 2. Again, the commercially available diol was employed as the starting material which was substituted with alkyloxy groups to produce 


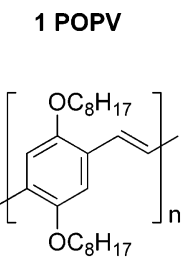

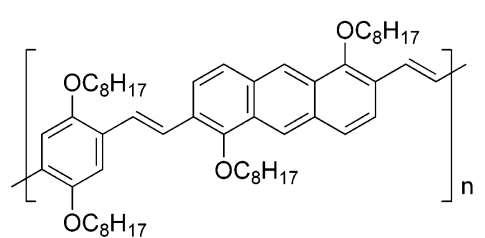

4 POPV-OAV

Figure 1. Structures of polymeric systems.

Scheme 1. Synthesis of Phenyl Intermediates

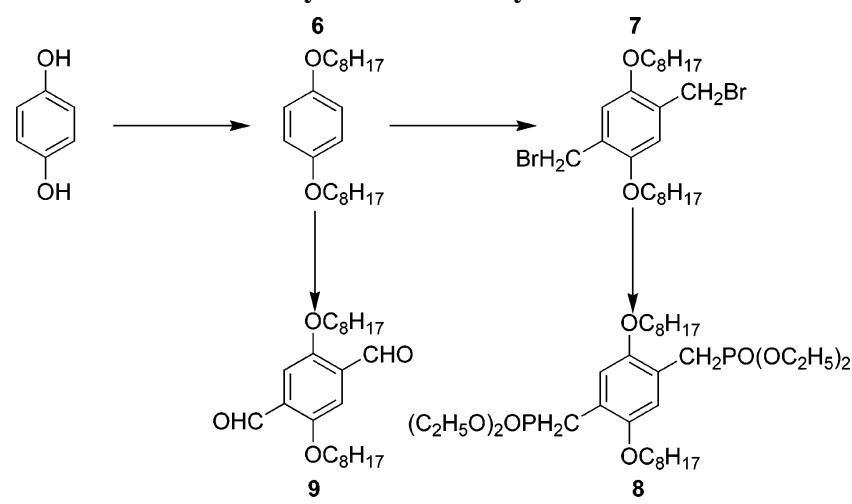

Scheme 2. Synthesis of Naphthalene Intermediates<smiles>Oc1cccc2c(O)cccc12</smiles><smiles>CCOc1cccc2c(OCC)cccc12</smiles>

$\mathrm{OH}$

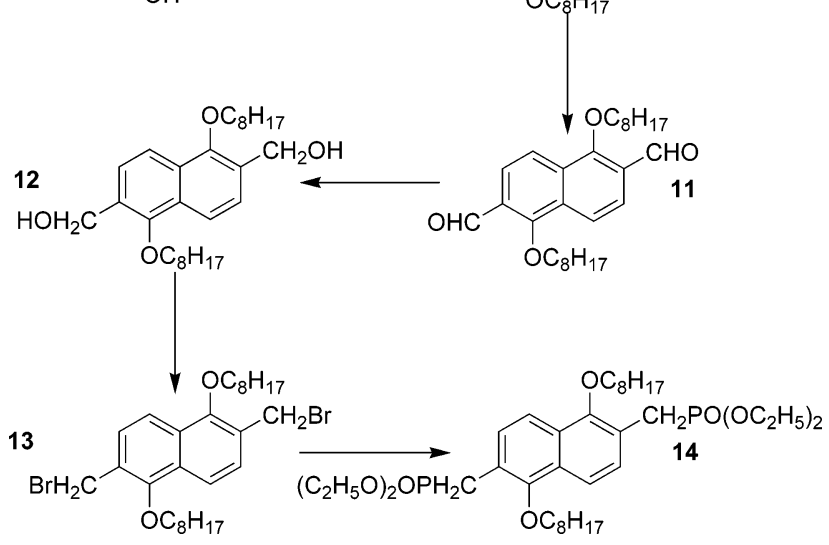

1,5-bis(n-octyloxy)naphthalene (10) using potassium carbonate as a base in MEK and giving $\mathbf{1 0}$ in $85 \%$ yield. In the case of the naphthalene derivatives bromomethylation of the alkyloxy derivative was not successful, and the bromomethylated product was therefore produced via the aldehyde. For lithiation of $\mathbf{1 0}$ hexane was employed as the solvent as it proved more efficient at solubilizing the monolithiated intermediate which precipitates from solution. Formylation again with DMF afforded 11 in 24\% yield. Reduction of $\mathbf{1 1}$ using stoichiometric equivalents of sodium borohydride produced 12, which was brominated with phosphorus tribromide to produce the desired 1,5-bis $(n$-octyloxy)-2,6-dibromomethylnaphthalene (13). In the Arbuzov reaction no excess of triethylphosphite was used, and 1,5-bis $(n-$
3 PONV<smiles>CCCC=Cc1ccc2c(OCC)c(C)ccc2c1OCC</smiles>

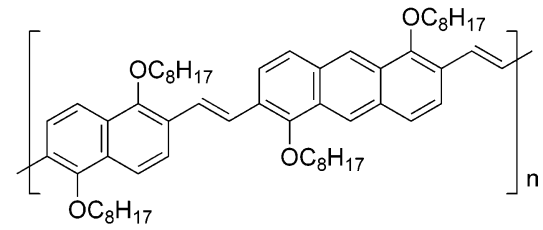

5 PONV-OAV

Scheme 3. Synthetic Route to the Anthracene Dialdehyde Starting Material
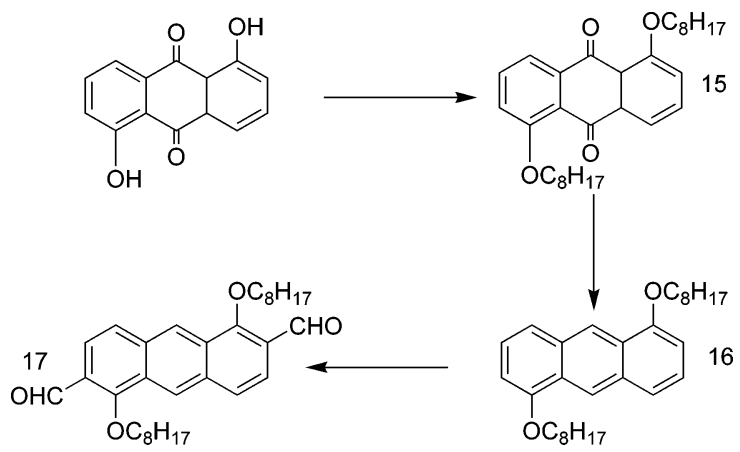<smiles>CCOc1cccc2cc3cccc(OCC)c3c(OCC)c12</smiles>

octyloxy)-2,6-dimethylnaphthalene-bis(ethylphosphonate ester) (14) was produced in $93 \%$ yield without purification as the product was unstable.

To produce the anthracene derivatives, anthracene-1,5-diol was not a suitable starting material as it is very sensitive to oxidation. ${ }^{27}$ Anthraquinone-1,5-diol was chosen instead. The synthetic route employed is shown in Scheme 3. For the addition of the octyloxy side chains the same method as that used for the naphthalene products was employed, but in this case DMF was found to be a better solvent, producing 1,5-bis(octyloxy)anthraqinone (15) in $42 \%$ yield. The reduction of the anthraquinone to 1,5-bis(octyloxy)anthracene (16) was attempted using various methods, ${ }^{28,29}$ but the reduction by sodium borohydride proved to be the most effective. ${ }^{27}$ It was found that addition of $5 \%$ water to the solvent system helped to drive the reaction to completion, giving improved yields of $64.5 \%$. Lithiation and formylation of the 2,6-positions was carried out as before, but in the case of the anthracene substrate the conditions were changed from a $24 \mathrm{~h}$ reflux to a $96 \mathrm{~h}$ room temperature stir for the lithiation step. The resultant 1,5-bis(noctyloxy)-2,6-anthracenedialdehyde (17) was produced in 39\% yield.

The polymerization route employed is shown in Scheme 4. Studies have shown that the Wittig-Horner reaction carried out at $80{ }^{\circ} \mathrm{C}$ employing $\mathrm{DMF}$ as the solvent produced the longest chain polymers in the highest yields. ${ }^{20}$ Therefore, these conditions were used to produce materials $\mathbf{1}-\mathbf{5}$.

The properties of each polymer are listed in Table 1 . Numberaverage molecular weight values were calculated by both NMR end-group analysis and gel permeation chromatography using polystyrene standards. This study revealed that both methods gave comparable results for all the polymers except PONV, for which a much higher molecular weight was obtained from NMR 
Scheme 4. Example Polymerization Route (in This Case to PONV-OAV)

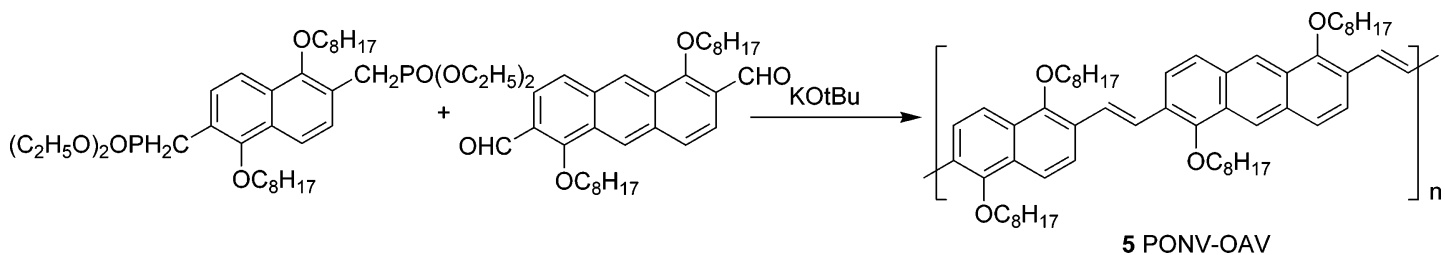

Table 1. Physical Properties of Polymers in the Series ${ }^{a}$

\begin{tabular}{|c|c|c|c|c|c|c|c|}
\hline polymer & $\lambda_{\max }(\mathrm{abs}), \mathrm{nm}$ & $\lambda_{\max }(\mathrm{em}), \mathrm{nm}$ & Stokes shift, eV & $M_{\mathrm{n}}(\mathrm{NMR}), \mathrm{g} / \mathrm{mol}$ & $M_{\mathrm{n}}(\mathrm{GPC}), \mathrm{g} / \mathrm{mol}$ & $M_{\mathrm{w}}(\mathrm{GPC}), \mathrm{g} / \mathrm{mol}$ & $M_{\mathrm{w}} / M_{\mathrm{n}}$ \\
\hline POPV (1) & 510 & 545 & 0.38 & 1745 & 1850 & 2530 & 1.37 \\
\hline POPV-ONV (2) & 480 & 510 & 0.31 & 6774 & 7020 & 17150 & 2.44 \\
\hline PONV (3) & 440 & 460 & 0.30 & 4237 & 1850 & 2110 & 1.14 \\
\hline POPV-OAV (4) & 500 & 520 & 0.09 & 6628 & 7040 & 13840 & 1.97 \\
\hline PONV-OAV (5) & 470 & 489 & 0.10 & 3285 & 3310 & 5330 & 1.61 \\
\hline
\end{tabular}

${ }^{a}$ The Stokes shift is the difference in energy between the $\lambda_{\max }$ absorbance and $\lambda_{\max }$ emission. $M_{\mathrm{n}}$ is the number-average molecular weight as determined by NMR end-group analysis and GPC. $M_{\mathrm{w}}$ is the weight-average molecular weight. $M_{\mathrm{w}} / M_{\mathrm{n}}$ was calculated from GPC data.

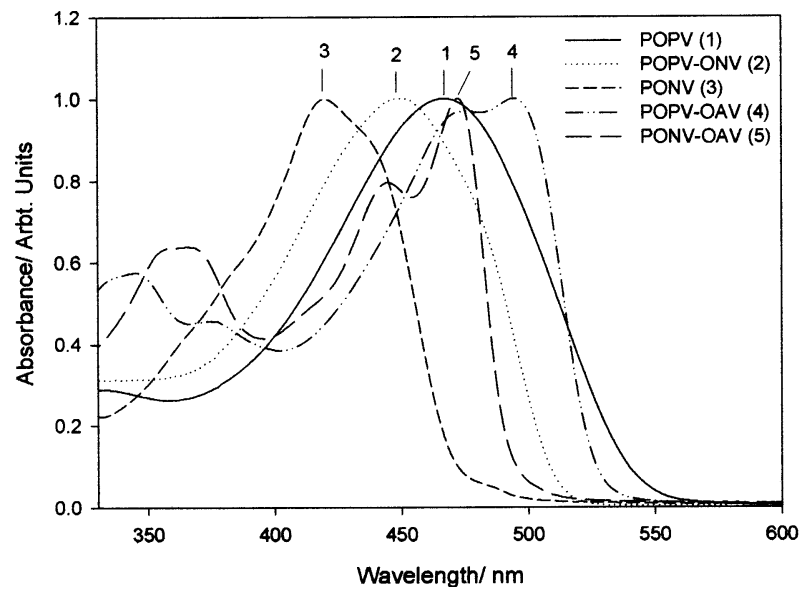

Figure 2. Absorption and emission spectra of polymers.

analysis. In all other cases GPC gave a slightly higher result. It is noted that while the same synthetic methods were employed, the copolymeric structures tended to have higher molecular weights. The solubilities of the copolymers are also less, and interestingly PONV (3) is more soluble than POPV (1), while POPV-OAV (4) is less soluble than PONV-OAV (5). PONV-OAV (5) is the least soluble polymer in the series, to the extent that a suitable quality ${ }^{13} \mathrm{C}$ NMR spectrum could not be obtained even with extended accumulations.

The molecular weights of these materials are too low to produce high quality thin films which is important for device manufacture. However, oligomeric studies of a range of $\pi$-conjugated systems have shown that the electronic properties asymptotically approach the infinite chain limit with an inverse conjugation limit dependence. ${ }^{30-34}$ In addition to electronelectron and electron-vibration coupling, excitations can be confined by backbone torsion and other morphological effects, limiting the effective conjugation length. As a result, studies have found that the electronic properties of extended polymers mirror their oligomeric counterparts with 3-5 repeating monomer units. ${ }^{35}$ With regard to PPV type polymers, it has been shown that, in terms of electronic properties, changes caused by increasing the conjugated length saturate at ca. 5-7 repeating units. ${ }^{36,37}$ To allow for direct comparison between the polymers within this series, this converts to $15-20$ conjugated bonds along the polymer backbone. The shortest oligomer POPV (1) has 15 conjugated bonds along its shortest length. Therefore, the chain lengths synthesized here are sufficient to represent extended $\pi$-systems for this study aimed at the elucidation of the effects

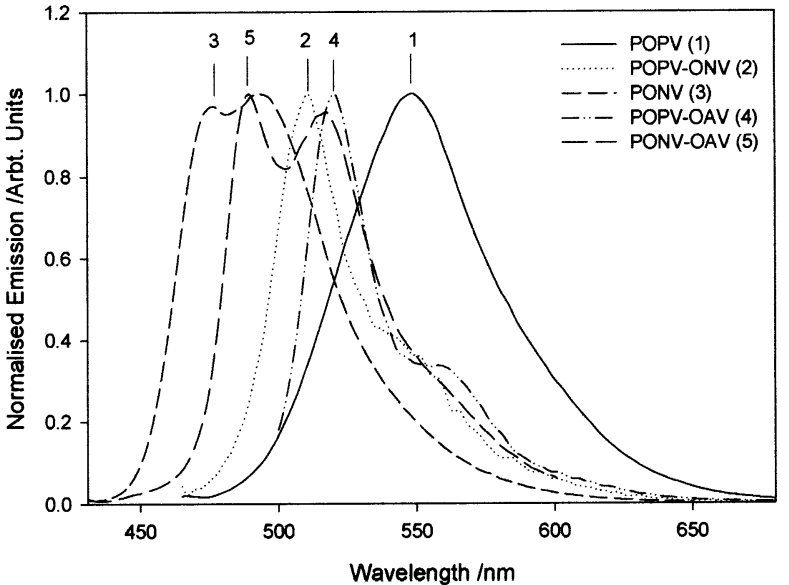

of structural variation on the electronic properties of the systems. Thus, while it is recognized that these systems are not truly polymeric, the phrase polymer rather oligomer is used throughout this paper.

The optical properties of the polymers are also shown in Table 1, and the absorption and emission spectra are shown in Figure 2. In both cases the maxima have been normalized to 1 .

Polymer POPV (1) was synthesized to allow for direct comparison of the optical properties of the later polymers in the series. It can be seen that replacement of phenyl units of the polymer backbone with naphthalene (2) results in a hypsochromatic shift in the spectra. This trend is continued in the all naphthyl polymer PONV (3). This was at first unexpected as we are introducing a more conjugated unit into the polymer backbone, and yet a blue shift characteristic of a decrease in the conjugation is observed. It can be seen that the introduction of the heavier electrophilic naphthyl units disrupts and hinders the formation of the conjugation along the backbone and as such increases the band gap and thus the absorption energy.

Contrary to what has been observed above, the introduction of the anthryl units into the backbone in the structure POPVOAV (4) results in a bathochromatic shift relative to its naphthalene counterpart POPV-ONV (2). The effective conjugation is now seen to increase with the introduction of the anthryl units. Finally, we observe that with the polymer PONVOAV (5) the spectra are hypsochromatically shifted relative to 4 yet red-shifted relative to 2 .

From the absorption wavelengths given in Table 1 we observe that the band gap increases as we add naphthalene units into 
the backbone while the Stokes shift decreases from 0.38 to 0.30 $\mathrm{eV}$. For the polymers containing anthryl units, the band gap is seen to decrease while the Stokes shift also decreases greatly to $0.09 \mathrm{eV}$.

As we have shown, sequential replacement of the phenyl units by naphthyl units results in an increasing hypsochromatic shift of both the absorption and emission spectra, indicating a disruption of the conjugation by the larger naphthyl units. The replacement of the naphthyl units by anthryl in the POPVOAV polymer reverses this trend. This behavior cannot be fully explained by steric interactions or bond torsions introduced by the substitution with bulkier aromatic units. This should induce a greater torsion or bond angle across the vinylene bond, and hence one would assume further disrupt the conjugation which would result in a hypsochromatic shift. As can be seen on going from POPV-ONV to POPV-OAV, there is no such blue shift. In order to understand this behavior, both the electronic contribution of the acene unit across the vinyl bond and the contribution of the acene unit itself to the electronic conjugation must be considered.

A study by Meier ${ }^{38}$ using a series of conjugated oligomers with terminal donor-acceptor substitution has shown that in these systems either a bathochromatic or a hypsochromatic shift can be affected, depending on the terminal groups. The systems were modeled to predict the spectral shifts affected by various donor and acceptor groups on the oligomers. It was found that the energy $E_{\mathrm{DA}}(n)$ of an electronic transition in such donor$[\pi]_{n}$-acceptor systems of $n$ repeating $\pi$ units can be split into two distinct and at times opposing factors: an increase in conjugation caused by the extension of the $\pi$ systems and the electron donating/accepting contribution of the terminal groups to the linking $\pi$ system. In the study a number of different cases were observable, depending on the relative contributions of the charge transfer compared to the increase of conjugation as the length of the conjugated linker was increased.

When the contribution of the conjugated linker is of the same order as that of the end groups, the effect of the different end groups can cause either a bathochromatic or a hypsochromatic shift. This is similar to that observed for the $\mathrm{T}-[\pi]_{n}-\mathrm{T}$ series POPV (1), POPV-ONV (2), and POPV-OAV (4) in which we approximate the interactions to a single acene unit of increasing length (i.e., phenyl, naphthyl, anthryl) to be the $[\pi]_{n}$ with constant terminating group $\mathrm{T}$ on either side, being in the case of this series a vinylene phenyl group. The competition between the increased conjugation of the linker unit and the electron donation to the end groups results in the reversal of hypsochromatic to bathochromatic shift as a function of $n$. Within our structures another similar series of POPV-ONV (2), PONV (3), PONV-OAV (5) occurs; in this case the T groups begin with a vinylene naphthyl linkage, and the electron donating/accepting contribution of the end groups is increased compared to the first series. We can model these series in a similar manner to Meier taking $E_{\text {infinity, the band gap of an }}$ infinitely long polyacene chain, as $1.3 \mathrm{eV} .{ }^{39}$

As can be clearly seen in Figure $3, E_{\mathrm{DA}}-E_{\text {infinity }}$ reaches a maximum as the acene unit goes from phenyl to naphthalene, and with further addition of fused rings the band gap begins to reduce again. The behavior of alternating bathochromatic/ hypsochromatic behavior observed experimentally for the polymers can thus be observed in the approximated oligomeric model. This behavior should be enhanced by the extension of the short chains to longer polymeric chains. Meier's model then does provide information on the variation on the polymers synthesized, albeit when considered as short chain molecules.

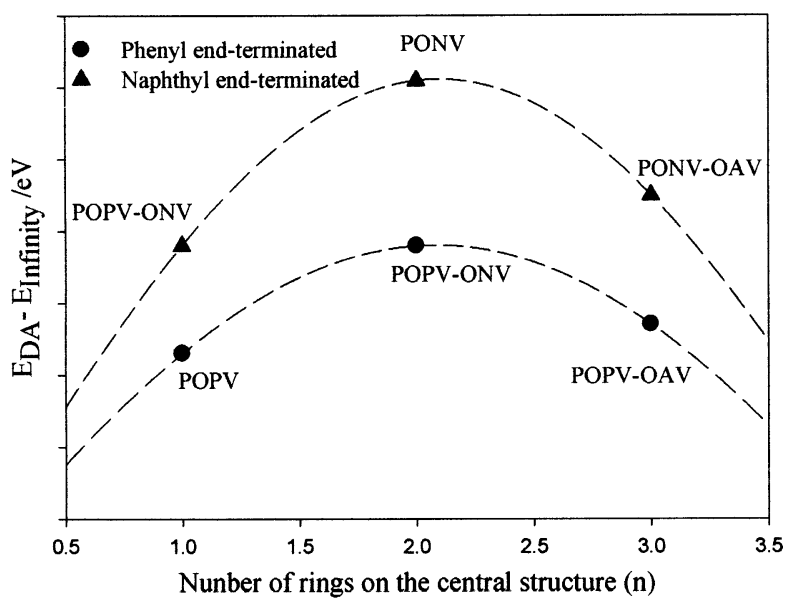

Figure 3. Plot of the variation of the band gap for the series with phenyl- and naphthyl-terminated oligo approximations.

Interestingly, in the oligomer studies published by Meier, it was noted that in the case where the oligomer showed an initial increase in absorption energy reaching a peak value a subsequent decrease was never observed experimentally. All previously studied systems reached a minimum energy which increased again to a higher energy. This work therefore extends the study of Meier.

It can be seen that the properties can be related in a predictable way to the structural variation. The inclusion of the naphthyl group as stated earlier disrupts the conjugated backbone, hence causing a hypsochromatic shift. Opposing this, inclusion of naphthalene into the polymer backbone would cause a red shift due to the increase in conjugation by the inclusion of the more conjugated units. However, with the naphthyl inclusion the backbone disruption is by far the greater effect and thus dominates the spectral changes. Inclusion of an anthryl unit results in an increase in conjugation. This increase far outweighs further disruption in the backbone by the anthryl unit. Thus, it is the substituent tendency to aid delocalization of electrons across the vinylene linkage and therefore along the polymer chain as well as the effective increase in conjugation of the higher order acene units that must be considered. With this in mind it is easy to see how anthryl substitution does have a very different effect on the band gap of the polymer when compared to naphthyl substitution.

Because of our synthetic strategy, the inclusion of side chains on every aromatic unit should minimize any inconsistencies in the model. A further discussion of the adapted model and its observed trend is outside the scope of this paper and can be found elsewhere. ${ }^{40}$

\section{Conclusion}

A series of novel polymers containing naphthalene and anthracene groups were synthsised by the Wittig-Horner polymerization. Their absorbance and emission spectra show a hypsochromatic shift due to the introduction of naphthyl units and a bathochromatic shift due to the introduction of anthryl units. The systematic changes made to each structure allows us to derive a relationship between order of the acene substituents and the properties of the polymers. The merits of the production of the systematically varied, homologous series can be seen through the ability to elucidate and understand the origin of the structure-property relationships.

\section{Experimental Section}

Characterization Techniques. NMR spectra were recorded in deuterated chloroform with tetramethylsilane (TMS) as an internal 
reference. Spectra of intermediate samples were obtained on a Varian Gemini 200 instrument with an Oxford 200 superconducting magnet. The system operates at $200 \mathrm{MHz}$ for ${ }^{1} \mathrm{H}$ and $50 \mathrm{MHz}$ for ${ }^{13} \mathrm{C}$ spectra. Spectra of the polymerization starting materials and polymer samples were obtained on a Bruker Avance 400. The system operates at $400 \mathrm{MHz}$ for ${ }^{1} \mathrm{H}$ and $100 \mathrm{MHz}$ for ${ }^{13} \mathrm{C}$ spectra.

FTIR spectra were recorded at room temperature using a PerkinElmer Spectrum GX FTIR spectrometer. This is a single-beam, Michelson interferometer based, Fourier transform infrared spectrometer. It has a dual level optical module that is sealed and desiccated. The system is configured with a mid-infrared single source. MIR and FIR beamsplitters and a DTGS detector allow the range $7000-50 \mathrm{~cm}^{-1}$ to be covered with a maximum resolution of $0.3 \mathrm{~cm}^{-1}$. The Spectrum GX is a modular system and can accommodate up to four equivalent output beams. The spectrometer is configured with the AutoIMAGE microscope system, which can operate in transmission or reflectance modes.

Spectra were obtained of solid samples as $\mathrm{KBr}$ disks, except where otherwise stated. The spectra were measured over a range of $4000-370 \mathrm{~cm}^{-1}$ with a resolution of $4 \mathrm{~cm}^{-1}$, an interval of 1 $\mathrm{cm}^{-1}$ and an accumulation of 64 .

$1 \times 10^{-5} \mathrm{~mol} \mathrm{dm}^{-3}$ solutions of the polymers were prepared in $\mathrm{CCl}_{4}$, and electronic absorption spectra were recorded using a Perkin-Elmer Lambda 900 UV/vis/NIR spectrometer. This spectrometer has a double-beam, double monochromator ratio recording system with tungsten-halogen and deuterium lamps as sources. The spectrometer has a range from 175 to $3300 \mathrm{~nm}$ with an accuracy of $0.08 \mathrm{~nm}$ in the $\mathrm{UV}-$ vis region. It has a photometric range of \pm 6 in absorbance.

The fluorescence spectra of the above samples were measured using a Perkin-Elmer LS55B luminescence spectrometer. Spectra were recorded using an attenuated scan method which has a $1 \%$ attenuation setting. The samples were excited at the $\lambda_{\max }$ of the absorption measured above. The spectrometer is a computercontrolled ratioing luminescence spectrometer with the capability of measuring fluorescence or phosphorescence. Excitation is provided by a pulsed xenon discharge lamp, of pulse width at half peak height of $<10 \mu \mathrm{s}$ and pulse power of $20 \mathrm{~kW}$. The source is monochromated using a Monk-Gillieson type monochromator with a range of $200-800 \mathrm{~nm}$. The excitation and emission slits can be varied from 2.5 to $15 \mathrm{~nm}$ in $0.1 \mathrm{~nm}$ increments. For this work they were set at $5 \mathrm{~nm}$.

For gel permeation chromatography (GPC) polymer solutions were injected $(100 \mu \mathrm{L})$ into a THF stream with a flow rate of 1 $\mathrm{cm}^{3} \mathrm{~min}^{-1}$. Polystyrene calibration standards were used. The pump was a Waters $600 \mathrm{E}$, and the columns were $7.8 \times 300 \mathrm{~mm}$ Styragel: HT3 (500-30000 A) HT5 (50000-4000000 A), and HT6E (5000-10000000 A). The detector employed was a Waters 410 differential spectrometer set at $260 \mathrm{~nm}$.

Syntheses. All solvents and reagents were obtained from SigmaAldrich and dried according to standard procedures as required.

Synthesis of 1,4-Di-n-octyloxybenzene (6). To DMSO $\left(92 \mathrm{~cm}^{3}\right.$, dried over $\mathrm{MgSO}_{4}$ ) powdered $\mathrm{KOH}(41.09 \mathrm{~g}, 0.73 \mathrm{~mol})$ was added. After stirring for $10 \mathrm{~min}, p$-hydroquinone $(20.35 \mathrm{~g}, 0.18 \mathrm{~mol})$ was added, followed immediately by octyl bromide $(71.08 \mathrm{~g}, 0.37 \mathrm{~mol})$. After stirring for $30 \mathrm{~min}$ the mixture was poured into water (552 $\mathrm{cm}^{3}$ ) and left to stand for $1.5 \mathrm{~h}$. The waxy product was collected by filtration and recrystallized from $n$-heptane. After filtration and drying white flakes of 1,4-di-n-octyloxybenzene were obtained (45.35 g, 73.8\%); melting range: $56-57{ }^{\circ} \mathrm{C} .{ }^{1} \mathrm{H}$ NMR $\left(\mathrm{CDCl}_{3}\right.$, ppm): 6.82 (s, 4H), 3.89 (t, 4H), 1.75 (qui, 4H), 1.59-1.29 (m, $20 \mathrm{H}), 0.88$ (t, 6H). ${ }^{13} \mathrm{C} \mathrm{NMR}\left(\mathrm{CDCl}_{3}, \mathrm{ppm}\right): 153.15,115.31,68.59$, 31.80, 29.37, 29.24, 26.04, 22.64, 14.09. FTIR ( $\mathrm{KBr}$ pellet, $\left.\mathrm{cm}^{-1}\right)$ : 2956 (vs), 2856 (vs), 1643 (w-m), 1513 (m), 1395 (m), 1290 (m), 1246 (vs), 1115 (m), 1031 (s), 827 (s), 728 (m), 535 (m).

Synthesis of 2,5-Di-n-octyloxy-1,4-bis(bromomethyl)benzene (7). A mixture of 1,4-di-n-octyloxybenzene $(12.20 \mathrm{~g}, 37 \mathrm{mmol})$, paraformaldehyde $(15.76 \mathrm{~g}, 53 \mathrm{~mol})$, and $\mathrm{KBr}(23.20 \mathrm{~g}, 0.20 \mathrm{~mol})$ was heated in acetic acid $\left(200 \mathrm{~cm}^{3}\right)$ to $80{ }^{\circ} \mathrm{C}$. A mixture of glacial acetic acid $\left(25 \mathrm{~cm}^{3}\right)$ and concentrated sulfuric acid $\left(20 \mathrm{~cm}^{3}\right)$ was added dropwise over $0.5 \mathrm{~h}$. After stirring for an additional $5 \mathrm{~h}$ at
$80{ }^{\circ} \mathrm{C}$ the mixture was left to stand overnight. The crystals were filtered off, washed with water until the acetic acid smell disappeared, and recrystallized from $n$-heptane to give pale yellow fluffy needles $(13.185 \mathrm{~g}, 73.1 \%)$; melting range: $87-88{ }^{\circ} \mathrm{C} .{ }^{1} \mathrm{H}$ NMR $\left(\mathrm{CDCl}_{3}, \mathrm{ppm}\right): 6.85(\mathrm{~s}, 2 \mathrm{H}), 4.52(\mathrm{~s}, 4 \mathrm{H}), 3.98(\mathrm{t}, 4 \mathrm{H}), 1.81$ (qui, $4 \mathrm{H}), 1.31-1.49(\mathrm{~m}, 20 \mathrm{H}), 0.889(\mathrm{t}, 6 \mathrm{H}) .{ }^{13} \mathrm{C} \mathrm{NMR}\left(\mathrm{CDCl}_{3}, \mathrm{ppm}\right)$ : $150.62,127.47,114.58,68.95,31.79,29.28,29.2$, 28.72, 26.05, 22.64, 14.01. FTIR (KBr pellet, $\mathrm{cm}^{-1}$ ): 2919 (vs), 2853 (s), 1509 (s), $1474(\mathrm{~m}), 1412(\mathrm{~s}), 1315(\mathrm{~m}), 1262$ (w), 1229 (s), 1043 (m), 859 (m-s), 729 (m), 689 (s) 546 (m), 454 (w-m).

Synthesis of 2,5-Di-n-octyloxy-1,4-xylene-Diethylphosphonate Ester (8). Triethylphosphite $(9.05 \mathrm{~g}, 52.12 \mathrm{mmol})$ and 2,5-di- $n$ octyloxy-1,4-bis(bromomethyl)benzene (13.00 g, $26.06 \mathrm{mmol}$ ) were heated to $150{ }^{\circ} \mathrm{C}$ for $4 \mathrm{~h}$, while the byproduct ethyl bromide was continuously removed by distillation. After filtration through cotton wool and recrystallization from petroleum ether, pale yellow crystals were obtained $(10.01 \mathrm{~g}, 71.4 \%)$; melting range $50-51{ }^{\circ} \mathrm{C} .{ }^{1} \mathrm{H}$ NMR $\left(\mathrm{CDCl}_{3}, \mathrm{ppm}\right): 6.92$ (s, 2H), 4.02 (qua, 8H), 3.92 (t, 4H), 3.28 (d, 4H) 1.77 (qui, 4H), $1.29-1.24(\mathrm{~m}, 32 \mathrm{H}), 0.89(\mathrm{t}, 6 \mathrm{H}) .{ }^{13} \mathrm{C} \mathrm{NMR}$ $\left(\mathrm{CDCl}_{3}, \mathrm{ppm}\right)$ : $150.25,119.27,114.75,68.83,61.70,31.67,29.26$, 29.12, 27.47, 25.99, 24.69, 22.51, 16.21, 13.94. FTIR (Nujol, $\mathrm{cm}^{-1}$ ):

2969 (vs), 2843 (s), 1510 (w), 1257 (s), 1213 (s), 1034 (vs), 959 (s), $882(\mathrm{~m}), 834(\mathrm{w}), 724(\mathrm{~m}), 641$ (m), $482(\mathrm{w})$.

Synthesis of 1,4-Bis(n-octyloxy)-2,5-phenyldialdehyde (9). A solution of 1,4-di- $n$-octyloxybenzene $(10.26 \mathrm{~g}, 30.6 \mathrm{mmol})$ and TMEDA $\left(24.0 \mathrm{~cm}^{3}, 159.9 \mathrm{mmol}\right)$ in diethyl ether $\left(450 \mathrm{~cm}^{3}\right)$ was cooled to $0{ }^{\circ} \mathrm{C}$ and bubbled with nitrogen for $10 \mathrm{~min}$. A $1.6 \mathrm{~mol}$ $\mathrm{dm}^{-3}$ solution of $n$-BuLi in hexane $\left(100 \mathrm{~cm}^{3}, 160 \mathrm{mmol}\right)$ was added dropwise over $30 \mathrm{~min}$. The mixture was stirred at $0{ }^{\circ} \mathrm{C}$ for $1 \mathrm{~h}$ and then slowly warmed to reflux. After being refluxed for $20 \mathrm{~h}$ the nitrogen was turned off; and the resulting green solution was cooled to $0{ }^{\circ} \mathrm{C}$, and DMF $\left(20 \mathrm{~cm}^{3}, 260 \mathrm{mmol}\right)$ was added dropwise. The mixture was stirred at $0{ }^{\circ} \mathrm{C}$ for $2 \mathrm{~h}$. Then $4 \mathrm{~mol} \mathrm{dm}^{-3} \mathrm{HCl}(95$ $\mathrm{cm}^{3}$ ) was added slowly with vigorous stirring. The resulting twophase system was stirred for an additional $30 \mathrm{~min}$. The organic layer was separated, washed with $0.5 \mathrm{~mol} \mathrm{dm}{ }^{-3} \mathrm{HCl}\left(150 \mathrm{~cm}^{3}\right)$, saturated $\mathrm{NaHCO}_{3}$ solution $\left(150 \mathrm{~cm}^{3}\right)$, and brine $\left(150 \mathrm{~cm}^{3}\right)$, and then dried over $\mathrm{MgSO}_{4}$. The solution was concentrated under reduced pressure to give a brown solid. The crude product was purified by column chromatography $(25 \mathrm{~cm}$, silica gel, DCM:hexane $1: 4)$ and left to crystallize as yellow needles (4.114 g, 34.5\%); melting range: $69-71{ }^{\circ} \mathrm{C} .{ }^{1} \mathrm{H}$ NMR $\left(\mathrm{CDCl}_{3}, \mathrm{ppm}\right): 10.52(\mathrm{~s}, 2 \mathrm{H})$, $7.42(\mathrm{~d}, 2 \mathrm{H}), 4.08(\mathrm{t}, 4 \mathrm{H}), 1.87$ (qui, 4H), 1.47-1.31 (m, 20H), $0.89(\mathrm{t}, 6 \mathrm{H}) .{ }^{13} \mathrm{C} \mathrm{NMR}\left(\mathrm{CDCl}_{3}, \mathrm{ppm}\right): 189.33,155.14,129.17$, 111.50, 69.14, 31.72, 29.17, 28.98, 25.96, 22.59, 14.03. FTIR (KBr pellet, $\mathrm{cm}^{-1}$ ): 2919 (s), 2852 (s), 1682 (vs), 1490 (m), 1470 (ms), 1388 (s), 1279 (m), 1216 (s), 1125 (m), 1060 (m), 881 (w), 718 (w), 453 (w), 819 (w).

Synthesis of 1,5-Di-n-octyloxynaphthalene (10). A solution of dihydroxynaphthalene (20.00 g, $125 \mathrm{mmol}), \mathrm{K}_{2} \mathrm{CO}_{3}(58.00 \mathrm{~g}, 420$ $\mathrm{mmol})$, and octyl bromide $(96.48 \mathrm{~g}, 500 \mathrm{mmol})$ in $\operatorname{MEK}\left(500 \mathrm{~cm}^{3}\right)$ was refluxed for $24 \mathrm{~h}$. The inorganic salts were filtered off and washed with hot toluene. The solution was concentrated under reduced pressure to give a greenish solid. The crude product was recrystallized with activated charcoal in toluene to give yellow crystals $(30.40 \mathrm{~g}, 63.3 \%)$; melting range: $85-86{ }^{\circ} \mathrm{C} .{ }^{1} \mathrm{H}$ NMR $\left(\mathrm{CDCl}_{3}, \mathrm{ppm}\right): 7.82(\mathrm{~d}, 2 \mathrm{H}),, 7.34(\mathrm{t}, 2 \mathrm{H}),, 6.83(\mathrm{~d}, 2 \mathrm{H}),, 4.11(\mathrm{t}$, 4H), 1.91 (qui, 4H,), 1.55 (qui, 4H), 1.48-1.32 (m, 16H,), 0.89 (t, $6 \mathrm{H},) .{ }^{13} \mathrm{C} \mathrm{NMR}\left(\mathrm{CDCl}_{3}, \mathrm{ppm}\right): 154.8,126.9,125.0,114.1,105.3$, 68.3, 31.9, 29.4, 29.36, 29.3, 26.3, 22.7, 14.1. FTIR (KBr pellet, $\mathrm{cm}^{-1}$ ): 2926 (s), 2852 (s), 1592 (s), 1509 (s), 1472 (m), 1388 (s), 1266 (vs), 1057 (s), 718 (w), 774 (s), 728 (m).

Synthesis of 1,5-Bis(n-octyloxy)-2,6-naphthalenedialdehyde (11). A solution of 1,5-dioctyloxynaphthalene (11.76 g, $30.6 \mathrm{mmol})$ and TMEDA $\left(24.0 \mathrm{~cm}^{3}, 159.9 \mathrm{mmol}\right)$ in hexane $\left(450 \mathrm{~cm}^{3}\right)$ in a nitrogen atmosphere was cooled to $0{ }^{\circ} \mathrm{C}$. A $1.6 \mathrm{~mol} \mathrm{dm}^{-3}$ solution of $n$-BuLi in hexane $\left(100 \mathrm{~cm}^{3}, 160 \mathrm{mmol}\right)$ was added dropwise over $30 \mathrm{~min}$. The mixture was stirred at $0{ }^{\circ} \mathrm{C}$ for $1 \mathrm{~h}$ and then slowly warmed to reflux. After being refluxed for $24 \mathrm{~h}$ the resulting solution was cooled to $0{ }^{\circ} \mathrm{C}$, and DMF $\left(20 \mathrm{~cm}^{3}, 260 \mathrm{mmol}\right)$ was added dropwise. The mixture was stirred at $0{ }^{\circ} \mathrm{C}$ for $2 \mathrm{~h}$. Then $4 \mathrm{~mol} \mathrm{dm}^{-3} \mathrm{HCl}(95$ 
$\mathrm{cm}^{3}$ ) was added slowly with vigorous stirring. The resulting twophase system was stirred for an additional $30 \mathrm{~min}$. The organic layer was separated, washed with $0.5 \mathrm{~mol} \mathrm{dm} \mathrm{dm}^{-3} \mathrm{HCl}\left(150 \mathrm{~cm}^{3}\right)$, saturated $\mathrm{NaHCO}_{3}$ solution $\left(150 \mathrm{~cm}^{3}\right)$, and brine $\left(150 \mathrm{~cm}^{3}\right)$, and then dried over $\mathrm{MgSO}_{4}$. The solution was concentrated under reduced pressure to give a brown solid. The crude product was purified by column chromatography (silica gel, DCM:hexane 1:4) and left to crystallize as a pale yellow solid (3.24 g, 24.1\%); melting range: $61-62{ }^{\circ} \mathrm{C} .{ }^{1} \mathrm{H}$ NMR $\left(\mathrm{CDCl}_{3}, \mathrm{ppm}\right): 10.50(\mathrm{~s}, 2 \mathrm{H}), 7.92$ (d, 2H), $7.86(\mathrm{~d}, 2 \mathrm{H}), 4.07$ (t, 4H), 1.84 (qui, 4H), 1.46 (qui, 4H), $1.21(\mathrm{~m}, 16 \mathrm{H}), 0.80(\mathrm{t}, 6 \mathrm{H}) .{ }^{13} \mathrm{C} \mathrm{NMR}\left(\mathrm{CDCl}_{3}, \mathrm{ppm}\right): 189.44$, $161.41,132.98,127.27,123.44,119.36,79.35,31.64,30.09,29.24$, 29.08, 25.81, 22.50, 13.95. FTIR ( $\mathrm{KBr}$ pellet, $\left.\mathrm{cm}^{-1}\right): 2958(\mathrm{~m})$, 2917 (s), 2852 (m), 1683 (vs), 1592 (m), 1467 (m), 1367 (m), 1327 (s), 12271056 (m), 822 (m), 723 (w).

Synthesis of 1,5-Bis(n-octyloxy)-2,6-dihydroxymethylnaphthalene (12). 1,5-Bis(n-octyloxy)-2,6-naphthalenedialdehyde (3.00 g, 7.4 mmol) was dissolved in absolute ethanol $\left(60 \mathrm{~cm}^{3}\right)$ and THF $\left(9 \mathrm{~cm}^{3}\right)$. $\mathrm{NaBH}_{4}(0.56 \mathrm{~g}, 14.8 \mathrm{mmol})$ was added at room temperature. After stirring for $4 \mathrm{~h}$ the reaction mixture was concentrated under reduced pressure. The residue was taken up in dichloromethane $\left(150 \mathrm{~cm}^{3}\right)$ and $3 \mathrm{~mol} \mathrm{dm}^{-3} \mathrm{HCl}\left(150 \mathrm{~cm}^{3}\right)$ with vigorous stirring. The organic layer was separated, and the aqueous layer was washed twice with dichloromethane $\left(75 \mathrm{~cm}^{3}\right)$. The combined organic layers were dried over $\mathrm{MgSO}_{4}$ and concentrated under reduced pressure to give a brownish solid (2.36 g 78.0\%); melting range: $65-67{ }^{\circ} \mathrm{C} .{ }^{1} \mathrm{H}$ NMR $\left(\mathrm{CDCl}_{3}, \mathrm{ppm}\right): 7.65(\mathrm{~d}, 2 \mathrm{H}), 7.40(\mathrm{~d}, 2 \mathrm{H}), 4.76(\mathrm{t}, 2 \mathrm{H}), 4.01(\mathrm{t}$, $4 \mathrm{H}), 2.45$ (d, 4H), 1.82 (qui, $4 \mathrm{H}), 1.46$ (qui, $4 \mathrm{H}), 1.23(\mathrm{~m}, 16 \mathrm{H}$, ), 0.82 (t, $6 \mathrm{H}) .{ }^{13} \mathrm{C} \mathrm{NMR}\left(\mathrm{CDCl}_{3}, \mathrm{ppm}\right): 152.85,129.26,126.61$, $118.43,113.96,75.41,60.64,31.81,30.38,29.24,26.22,26.06$, 22.63, 14.09. FTIR ( $\mathrm{KBr}$ pellet, $\mathrm{cm}^{-1}$ ): 3283 (s, br), 2953 (s), 2917 (s), 2852 (s), 1505 (m), 1498 (m), 1471 (s), 1377 (s), 1349 (s), 1232 (m) 1049 (s), 1004 (s), 815 (s) 719 (m).

Synthesis of 1,5-Bis(n-octyloxy)-2,6-dibromomethylnaphthalene (13). 1,5-Bis(n-octyloxy)-2,6-dihydroxymethylnaphthalene (2.00 g, $4.8 \mathrm{mmol})$ was dissolved in THF $\left(40 \mathrm{~cm}^{3}\right)$. Pyridine $\left(0.18 \mathrm{~cm}^{3}\right)$ was added, and the reaction mixture was cooled to $0{ }^{\circ} \mathrm{C}$. Phosphorus tribromide $\left(0.6 \mathrm{~cm}^{3}, 6.31 \mathrm{mmol}\right)$ was added within $5 \mathrm{~min}$, giving a white precipitate. The reaction mixture was allowed to warm to room temperature, stirred for $20 \mathrm{~h}$, and then concentrated under reduced pressure. The residue was taken up in toluene $\left(65 \mathrm{~cm}^{3}\right)$ and water $\left(100 \mathrm{~cm}^{3}\right)$. The organic layer was separated, and the aqueous layer was extracted twice with toluene $\left(20 \mathrm{~cm}^{3}\right)$. The combined organic layers were dried with $\mathrm{MgSO}_{4}$ and concentrated under reduced pressure to give an off-white solid. The crude product was purified by column chromatography ( silica gel, toluene) to give a white solid $(1.86 \mathrm{~g}, 72.3 \%)$; melting range $89-90{ }^{\circ} \mathrm{C}$. ${ }^{1} \mathrm{H}$ NMR $\left(\mathrm{CDCl}_{3}, \mathrm{ppm}\right): 7.83$ (d, 2H), $7.51(\mathrm{~d}, 2 \mathrm{H}), 4.74(\mathrm{~s}, 2 \mathrm{H}), 4.10$ (t, 4H), 197 (qui, 4H), 1.55 (qui, 4H), 31 (multi, 14H), 0.91 (t, 6H). ${ }^{13} \mathrm{C} \mathrm{NMR}\left(\mathrm{CDCl}_{3}, \mathrm{ppm}\right): 153.85,129.91,127.00,114.65,105.18$, 68.11, 31.82, 30.40, 29.26, 28.20, 26.24, 22.65, 14.09. FTIR ( $\mathrm{KBr}$ pellet, $\left.\mathrm{cm}^{-1}\right)$ : $2954(\mathrm{~m}), 2923(\mathrm{~s}), 2856$ (s), $1601(\mathrm{~m}), 1481(\mathrm{~m})$, 1471 (s), 1367 (s), 1335 (s), 1239 (m), 1204 (m), 1066 (s), 825 (s) $730(\mathrm{~m}), 559(\mathrm{~s})$.

Synthesis of 1,5-Bis(n-octyloxy)-2,6-dimethylnaphthalene-Bis(ethylphosphonate ester) (14). A mixture of 1,5-bis(n-octyloxy)2,6-dibromomethylnaphthalene $(0.57 \mathrm{~g}, 1 \mathrm{mmol})$ and triethylphosphite $(0.33 \mathrm{~g}, 2 \mathrm{mmol})$ was heated at $150{ }^{\circ} \mathrm{C}$ for $4 \mathrm{~h}$, while the byproduct ethyl bromide was continuously removed by distillation. After leaving the viscous liquid overnight at $4{ }^{\circ} \mathrm{C}$ yellow low melting crystals formed in the flask $(0.63 \mathrm{~g}, 93 \%) .{ }^{1} \mathrm{H} \mathrm{NMR}\left(\mathrm{CDCl}_{3}\right.$, ppm): $7.78(\mathrm{~d}, 2 \mathrm{H}), 7.75(\mathrm{~d}, 2 \mathrm{H}), 4.05$ (qui, 8H), 4.03 (t, 4H), 3.38 (d, 4H), 1.93 (qui, 4H), 1.57 (qui, 4H), 1.41-1.24 (m, 16H), 0.90 (t, 6H). ${ }^{13} \mathrm{C} \mathrm{NMR}\left(\mathrm{CDCl}_{3}, \mathrm{ppm}\right): 153.6,129.1,128.3,120.6$, $118.1,75.1,62.1,31.8,30.5,29.9,29.5,29.3,26.6,22.6,16.3,14.0$.

Synthesis of 1,5-Dioctyloxyanthraqinone (15). A solution of anthraquinone-1,5-diol (10.00 g, $41.3 \mathrm{mmol})$, potassium carbonate (19.32 g, $139.8 \mathrm{mmol})$, and octyl bromide (32.14 g, $166.2 \mathrm{mmol})$ in DMF $\left(300 \mathrm{~cm}^{3}\right)$ was heated to reflux for $24 \mathrm{~h}$. The inorganic salts were filtered and washed with hot toluene $\left(3 \times 50 \mathrm{~cm}^{3}\right)$. The filtrate was evaporated under reduced pressure; the resulting dark red solid was filtered using a short column (silica gel, diethyl ether) and recrystallized from methanol to give yellow crystals $(9.56 \mathrm{~g}$, 49.6\%); melting range: $90-92{ }^{\circ} \mathrm{C} .{ }^{1} \mathrm{H}$ NMR $\left(\mathrm{CDCl}_{3}, \mathrm{ppm}\right): 7.91$ (d 2H), $7.65(\mathrm{t} 2 \mathrm{H}), 7.26(\mathrm{~d} 2 \mathrm{H}), 4.15(\mathrm{t} 4 \mathrm{H}), 1.95$ (qui 4H), 1.541.31 (m 20H), 0.87 (t $6 \mathrm{H}) .{ }^{13} \mathrm{C} \mathrm{NMR}\left(\mathrm{CDCl}_{3}, \mathrm{ppm}\right):$ 182.57, $159.37,137.52,134.77,122.42,119.49,117.79,69.66,31.82,29.31$, 29.20, 29.11, 25.93, 22.66, 14.10. FTIR ( $\mathrm{KBr}$ pellet, $\left.\mathrm{cm}^{-1}\right): 2928$ (vs), 2849 (vs), 1675 (s), 1589 (s), 1467 (s), 1443 (s), 1279 (vs) 1169 (m), 1073 (s) 799 (s), 708 (s), 601 (m).

Synthesis of 1,5-Dioctyloxyanthracene (16). A solution of 1,5dioctyloxyanthraqinone $(1.00 \mathrm{~g}, 2.15 \mathrm{mmol})$ and sodium borohydride $(2.50 \mathrm{~g}, 66.08 \mathrm{mmol})$ in 2-propanol $\left(30 \mathrm{~cm}^{3}\right)$ and water $(1.5$ $\left.\mathrm{cm}^{3}\right)$ was refluxed for $24 \mathrm{~h}$ before being poured into ice water (100 $\mathrm{cm}^{3}$ ). The $\mathrm{pH}$ was slowly adjusted to between 4 and 6 with $6 \mathrm{M}$ $\mathrm{HCl}$. The crude product was filtered. The product was purified by flash chromatography (silica gel, 1:4 DCM:hexane) to yield a white product $(0.60 \mathrm{~g}, 64.5 \%)$; melting range: $114-119{ }^{\circ} \mathrm{C} .{ }^{1} \mathrm{H}$ NMR $\left(\mathrm{CDCl}_{3}, \mathrm{ppm}\right): 8.78(\mathrm{~s} 2 \mathrm{H}), 7.64(\mathrm{~d} 2 \mathrm{H}), 7.33(\mathrm{t} 2 \mathrm{H}), 6.74(\mathrm{~d} 2 \mathrm{H})$, $4.19(\mathrm{t} 4 \mathrm{H}), 2.00$ (qui 4H), $1.62-1.32(\mathrm{~m} \mathrm{20H}), 0.902(\mathrm{t} 6 \mathrm{H}) .{ }^{13} \mathrm{C}$ NMR $\left(\mathrm{CDCl}_{3}, \mathrm{ppm}\right): 154.86,132.26,125.53,124.99,120.87$, $120.49,102.64,68.27,31.87,29.45,29.29,26.36,22.68,14.08$. FTIR (KBr pellet, $\mathrm{cm}^{-1}$ ) 2922 (vs), 2850 (vs), 1622 (s), 1542 (s), 1390 (m), 1275 (s), 896 (m), 720 (s).

Synthesis of 1,5-Bis(n-octyloxy)-2,6-anthracenedialdehyde (17). A solution of 1,5-dioctyloxyanthracene $(1.35 \mathrm{~g}, 3.1 \mathrm{mmol})$ and TMEDA $\left(3.75 \mathrm{~cm}^{3}, 25.1 \mathrm{mmol}\right)$ in hexane $\left(50 \mathrm{~cm}^{3}\right)$ was cooled to $0{ }^{\circ} \mathrm{C}$, and a $1.6 \mathrm{M}$ solution of $n$-BuLi in hexane $\left(15.5 \mathrm{~cm}^{3}, 24.8\right.$ $\mathrm{mmol}$ ) was added dropwise over $30 \mathrm{~min}$. The mixture was stirred at $0{ }^{\circ} \mathrm{C}$ for $1 \mathrm{~h}$ and was then slowly warmed to room temperature. After being stirred for $96 \mathrm{~h}$ the resulting solution was cooled to $0{ }^{\circ} \mathrm{C}$, and DMF $\left(4 \mathrm{~cm}^{3}, 51.6 \mathrm{mmol}\right)$ was added dropwise. The mixture was stirred at $0{ }^{\circ} \mathrm{C}$ for $2 \mathrm{~h}$. Then $4 \mathrm{M} \mathrm{HCl}\left(8 \mathrm{~cm}^{3}\right)$ was added slowly with vigorous stirring. The resulting two-phase system was stirred for an additional $30 \mathrm{~min}$. The organic layer was separated, washed with $0.5 \mathrm{M} \mathrm{HCl}\left(15 \mathrm{~cm}^{3}\right)$, saturated $\mathrm{NaHCO}_{3}$ $\left(15 \mathrm{~cm}^{3}\right)$ solution, and brine $\left(15 \mathrm{~cm}^{3}\right)$, and then dried over $\mathrm{MgSO}_{4}$. The solution was concentrated under reduced pressure, and the crude product was purified by flash column chromatography (silica gel, DCM:hexane $1: 1)$ to yield a bright yellow powder $(0.7 \mathrm{~g}, 39.76 \%)$; melting range: $86-88{ }^{\circ} \mathrm{C} .{ }^{1} \mathrm{H} ~ \mathrm{NMR}\left(\mathrm{CDCl}_{3}, \mathrm{ppm}\right): 10.57(\mathrm{~s} 2 \mathrm{H})$ $8.73(\mathrm{~s} 2 \mathrm{H}) 7.79(\mathrm{~d} 4 \mathrm{H}), 4.22(\mathrm{t} 4 \mathrm{H}), 1.97$ (qui 4H), 1.60-1.25 (m $20 \mathrm{H}), 0.83$ (t $6 \mathrm{H}) .{ }^{13} \mathrm{C} \mathrm{NMR}\left(\mathrm{CDCl}_{3}, \mathrm{ppm}\right): 188.30,161.537$, $133.88,127.76,124.30,124.06,122.71,121.15,78.56,30.72,29.33$, 28.33, 28.16, 24.95, 21.55, 12.98. FTIR ( $\mathrm{KBr}$ pellet, $\left.\mathrm{cm}^{-1}\right): 2922$ (vs), 1679 (vs), 1401 (m), 1378 (m), 1350 (m), 1228(s), 809 (m), $768(\mathrm{~m}), 711(\mathrm{~m})$.

General Procedure for Polymerizations. A solution of diphosphonate ester $(1 \mathrm{mmol})$ and dialdehyde $(1 \mathrm{mmol})$ in DMF $\left(20 \mathrm{~cm}^{3}\right)$ was heated to $80^{\circ} \mathrm{C}$. Potassium tert-butoxide (KOtBu) $(2.67 \mathrm{mmol})$ was added at once. The reaction mixture was stirred at $80^{\circ} \mathrm{C}$ for an additional $4 \mathrm{~h}$ and then poured into water $\left(75 \mathrm{~cm}^{3}\right)$. The suspension thus formed was extracted four times with toluene (15 $\mathrm{cm}^{3}$ ). The organic layer was washed with water and dried over $\mathrm{MgSO}_{4}$. The solution was then concentrated by rotary evaporation, and the product precipitated with methanol. Finally, any monomeric material was removed by Soxhlet extraction with methanol for $24 \mathrm{~h}$.

Poly[ $p$-2,5-bis(n-octyloxy)phenylvinylene], POPV (1). Yield: $0.19 \mathrm{~g}(24.0 \%)$ of a red powder. ${ }^{1} \mathrm{H}$ NMR $\left(\mathrm{CDCl}_{3}, \mathrm{ppm}\right): 7.50$, 7.15, 4.05, 1.86, 1.52, 1.29, 0.87. ${ }^{13} \mathrm{C} \mathrm{NMR}\left(\mathrm{CDCl}_{3}, \mathrm{ppm}\right): 151.1$, $127.5,123.3,110.6,69.5,31.9,29.45,29.6,29.5,29.4,29.3,26.3$, 22.7, 14.1. FTIR (KBr pellet, $\mathrm{cm}^{-1}$ ): 2924 (s), 2852 (s), $1684(\mathrm{w})$, 1507 (s), 1466 (m), 1207 (s), 1069 (m), 965 (m-s), 850 (w).

Poly(2,5-bis(n-octyloxy)-1,4-phenylenevinylene-1,5-bis(n-octyloxy)-2,6-naphthalenevinylene), POPV-ONV (2). Yield: $0.375 \mathrm{~g}$ $(87.4 \%)$ of an orange powder. ${ }^{1} \mathrm{H} \mathrm{NMR}\left(\mathrm{CDCl}_{3}, \mathrm{ppm},\right): 8.25,7.79$, 7.88, 7.58, 4.05, 1.84, 1.54, 1.25, 0.83. ${ }^{13} \mathrm{C} \mathrm{NMR}\left(\mathrm{CDCl}_{3}, \mathrm{ppm}\right)$ : 153.2, 151.2, 129.5, 127.6, 127.0, 123.8, 123.1, 118.7, 110.3, 75.1, 69.6, 31.9, 29.7, 29.6, 29.5, 29.3, 26.4, 22.7, 14.1. FTIR (KBr pellet, $\mathrm{cm}^{-1}$ ): 3059 (w), 2957 (s), 2926 (vs), 2855 (s), 1681 (w), 1613 (w), 1496 (m), 1468 (m), 1262 (s), 1203 (m), 1028 (vs), 802 (vs). 
Poly(2,6-bis(n-octyloxy)-1,5-naphthalenevinylene), PONV (3). Yield: $0.087 \mathrm{~g}(44.4 \%)$ of a yellow powder. ${ }^{1} \mathrm{H}$ NMR $\left(\mathrm{CDCl}_{3}\right.$, ppm): 7.83, 7.35, 6.83, 4.12 1.93, 1.53, 1.32, 0.91. ${ }^{13} \mathrm{C}$ NMR $\left(\mathrm{CDCl}_{3}, \mathrm{ppm}\right): 154.7,126.8,125.1,114.0,105.2,68.2,31.9,29.4$, 29.35, 29.3, 26.3, 22.7, 14.2. FTIR ( $\mathrm{KBr}$ pellet, $\left.\mathrm{cm}^{-1}\right)$ : $2962(\mathrm{~s})$, 2923 (vs), 2853 (s), 1685 (m), 1611 (w), 1466 (w), 1407 (w), 1343 (w), 1262 (vs), 1097 (vs), 1029 (vs), 802 (vs).

$\operatorname{Poly}(2,5$-bis(n-octyloxy)-1,4-phenylvinylene-co-2,6-bis(n-octyloxy)-1,5-anthracenevinylene), POPV-OAV (4). Yield: $0.262 \mathrm{~g}$ (32.0\%) of a deep red solid. ${ }^{1} \mathrm{H}$ NMR $\left(\mathrm{CDCl}_{3}, \mathrm{ppm}\right)$ : 8.64, 7.83, $7.64,7.25,4.15,2.43,1.86 .1 .63-1.33,0.90 .{ }^{13} \mathrm{C} \mathrm{NMR}\left(\mathrm{CDCl}_{3}\right.$, ppm): 152.6, 151.2, 132.7, 127.6, 125.6, 124.9, 123.8, 123.4, 123.1, $121.3,110.3,69.6,31.9,30.7,29.7,29.6,29.5,29.4,26.5,26.4$, 22.7, 14.1. FTIR (KBr pellet, $\mathrm{cm}^{-1}$ ): 2925 (vs), 2854 (s), 1678 (m), 1618 (w), 1467 (w-m), 1467 (s), 1332 (m), 1259 (s), 1202 (s), $1102(\mathrm{~s}), 971(\mathrm{~m}), 802(\mathrm{~m})$.

Poly(2,6-bis(n-octyloxy)-1,5-naphthalenevinylene-co-2,6-bis $(n$ octyloxy)-1,5-anthracenevinylene), PONV-OAV (5). Yield: 0.358 $\mathrm{g}(43.7 \%)$ of an orange solid. ${ }^{1} \mathrm{H} \mathrm{NMR}\left(\mathrm{CDCl}_{3}, \mathrm{ppm}\right): 8.59,8.02$, 7.90, 7.82-7.76, 4.00, 1.98, 1.51-1.18, 0.84. FTIR (KBr pellet, $\mathrm{cm}^{-1}$ ): 2963 (s), 2925 (s), 2854 (s), 1682 (w), 1616 (w), 1468 (m), 1376 (w), 1262 (vs), 1098 (vs), 1023 (vs), 802 (vs).

Acknowledgment. We thank Dr. Manuel Ruether and Anna Drury from Trinity College Dublin for the GPC measurements and the Royal College of Surgeons Ireland for use of their NMR facilities. The Focas Institute is funded under the National Development Plan 2000-2006 with assistance from the European Regional Development Fund. P. Lynch acknowledges DIT Scholarship support.

Supporting Information Available: Proton NMR's of polymerization starting materials and polymers. This material is available free of charge via the Internet at http://pubs.acs.org.

\section{References and Notes}

(1) Burroughes, J. H.; Bradley, D. D. C.; Brown, A. R.; Marks, R. N.; Mackay, K. D.; Friend, R. H.; Burns, P. L.; Holmes, A. B. Nature (London) 1990, 347, 539

(2) Kim, Y.; Bradley, D. D. C. Curr. Appl. Phys. 2005, 5, 3, 222-226

(3) Hanack, M.; Segura, J. L.; Spreitzer, H. Adv. Mater. 1996, 8, 8.

(4) Behnisch, B.; Mariinez-Ruiz, P.; Schweikart, K-H.; Hanack, M. Eur. J. Org. Chem. 2000, 2541

(5) Maier, S.; Dury, A.; Davey, A. P.; Byrne, H. J.; Blau, W. J. Synth. Met. 2001, 119, 85.

(6) Van Dr Borght, M.; Vanderzande, D.; Gelan, J. Polymer 1998, 39,

(7) Segura, J. L. Acta Polym. 1998, 49, 319.
(8) Garay, R. O.; Naarmann, H.; Müllen, K. Macromolecules 1994, 27 7, 1922.

(9) Mullner, R.; Cravino, A.; Williams, J.; Stelzer, F.; Jakopic, G.; Leising, G. Synth. Met. 2001, 119, 193.

(10) Koch, F.; Heitz, W. Macromol. Chem. 1997, 198, 1531.

(11) Gilich, H. G.; Wheelwright, W. L. J. Polym. Sci., Part A: Polym. Chem. 1996, 4, 1337.

(12) Rrhan, M.; Schluetter, A. D. Macromol. Rapid Commun. 1990, 375.

(13) Wessling, R. A. J. Polym. Sci., Polym. Symp. 1986, 72, 55.

(14) Pfeiffer, S.; Hörhold, H.-H. Synth. Met. 1999, 101, 109.

(15) Drefahl, G.; Kuehmstedt, R.; Oswald, H.; Hörhold, H.-H. Macromol Chem. 1970, 131, 89 .

(16) Hörhold, H.-H.; Opfermann, J. Macromol. Chem. 1970, 131, 105.

(17) Rost, H.; Pfeiffer, S.; Teuschel, A.; Hörhold, H.-H. Synth. Met. 1997, 84, 269.

(18) Sim Chuah, B.; Geneste, F.; Holmes, A. B.; Martin, R. E.; Henning, R.; Cacialli, F.; Friend, R. H.; Hörhold, H.-H.; Pfeiffer, S.; Hwang, D.-H. Macromol. Symp. 2000, 154, 177.

(19) Egbe, D. A. M.; Kietzke, T.; Carbonnier, B.; Mühlbacher, D.; Hörhold H.-H.; Neher, D.; Pakula, T. Macromolecules 2004, 37, 8863.

(20) Dury, A.; Maier, S.; Rüther, M.; Blau, W. J. J. Mater. Chem. 2003, $13,485$.

(21) Johnstone, R. A. W.; Rose, M. E. Tetrahedron 1979, 35, 2169.

(22) Nierengarten, J. F.; Gu T. Helv. Chim. Acta 2004, 87, 11, 2948

(23) Gomez-Escalonilla, M. J.; Langa, F.; Rueff, J. M.; Oswald, L.; Nierengarten, J. F. Tetrahedron Lett. 2002, 43, 7507.

(24) Detert, H.; Sugiono, E. J. Phys. Org. Chem. 2000, 13, 587.

(25) Detert, H.; Schollmeyer, D.; Sugiono, E. Eur. J. Org. Chem. 2001 $15,2927$.

(26) Crowther, G. P.; Sundberg, R. J.; Sarpeshkar, A. M. J. Org. Chem 1984, 49, 4657

(27) Tius, M. A.; Gomez-Galeno, J.; Gu, X.; Zaidi, H. J. Am. Chem. Soc 1991, 113, 5775 .

(28) Sangaiah, R.; Gold, A. J. Org. Chem. 1987, 52, 3205.

(29) Mallory, F. B.; Mallory, C, W.; Baker, B. B. J. Am. Chem. Soc. 1990 $112,2577$.

(30) Kuhn, H. Fortsch. Chem. Org. Naturstoffe. 1958, 16, 169

(31) Rustagi, K. C.; Ducuing, J. Opt. Commun. 1974, 10, 3, 258.

(32) Nguyen, T. P.; Tran, V. H.; Destruel, P.; Oelkrug, D. Synth. Met. 1999, $101,633$.

(33) Martin, R. E.; Gubler, U.; Cornil, J.; Balakina, M.; Boudon. C.; Bosshard, C.; Gisselbrecht, J. P.; Diederich, F.; Günter, P.; Gross, M.; Brédas, J. L. Chem.-Eur. J. 2000, 6, 19, 3622.

(34) Oelkrug, D.; Gierschner, J.; Egelhaaf, H. J.; Lüer, L.; Tompert, A.; Müllen, K.; Stalmach, U.; Meier, H. Synth. Met. 2001, 121, 1693.

(35) Dostál, J.; Śimek, L.; Bohdanecký, M. Polym. Bull. (Berlin) 1998, $41,123$.

(36) Tian, B.; Zerbi, G.; Müllen, K. J. Chem. Phys. 1991, 95, 5, 3198.

(37) Yu, J.; Lin, S. H.; Synth. Met. 1997, 85, 1115

(38) Meier, H. Angew. Chem., Int. Ed. 2005, 44, 2482.

(39) Houk, K. N.; Lee, P. S.; Nendel, M. J. Org. Chem. 2001, 66, 5517.

(40) O’Neill, L.; Lynch, P.; McNamara, M.; Byrne, H. J. J. Phys. Chem. B 2007, 111, 299

MA070888C 